\title{
A Review on Microgrid Protection Using Superconducting Fault Current Limiter
}

\author{
M. Poornachandra Reddy and M. Manimozhi* \\ School of Electrical Engineering, Vellore Institute of Technology, India \\ E-mail:poornachandra.sr@gmail.com; mmanimozhi@vit.ac.in \\ ${ }^{*}$ Corresponding Author
}

Received 28 February 2018; Accepted 12 June 2018; Publication 18 July 2018

\begin{abstract}
A cluster of distributed generation (DG) is a Microgrid (MG) and load which acts as a heavy load or source in the context of actual grid. The sudden gust in the microgrid causes rise in fault current which surpasses the shortcircuit limit of network equipment by microgrid connection and also the increase in penetration of DG into the grid, the fault current level is also increased simultaneously. In order to overcome this problem, fault current limiter (FCL) could be arranged between the main network and microgrid. There are different types of FCLs, which have various designs and are made of various superconducting materials. Superconducting Fault Current Limiter (SFCL) is revolutionary protective device which has the ability to lower the fault current level within the fault current first cycle. The application of the SFCL would not only reduce the burden on network devices, but also offers connection for the betterment of the power system reliability. SFCL's are broadly classified into three types: inductive, resistive and hybrid SFCL. In this paper, general characteristics of FCLs, the operating characteristics, current limiting capabilities of SFCL are introduced into a simplified microgrid model system which is finally allowed that SFCL could reasonably bring about the function of microgrid stability improvement and fault current suppression.
\end{abstract}

Journal of Green Engineering, Vol. 8_2, 89-124. River Publishers

doi: 10.13052/jge1904-4720.821

This is an Open Access publication. (c) 2018 the Author(s). All rights reserved. 
Keywords: Distributed generation (DG), Microgrid (MG), Superconducting Fault Current Limiter (SFCL), fault current limiter (FCL), relays.

\section{Introduction}

Microgrids are limited to Low Voltage (LV) supply systems intended to supply heat and electrical loads for a limited area [1]. Microgrid can provide electricity, heat and also can reduce emissions, enhance the local reliability, improve power quality, control flexibility, and can greatly minimize the costs of power generation \& transmission [2,3]. Because of this reason, engineers thought of integrating various small generators called Micro Sources (MSs)/Distributed Generators (DGs $<500 \mathrm{~kW}$ ) solar power plants, wind, micro turbine, gas turbines, Combined Heat and Power (CHP), fuel cell and small hydroelectric power plant as a group, near the low voltage side to fulfil the essential demand, thus developing a novel trend known as "Microgrid" [4]. Microgrid are constructed by the integration of Distributed Energy Resources (DERs), Distributed Generation (DG), Energy Storage Systems (ESS), Electric Vehicles (EV) and electric consumers with smart energy meters and adjustable loads [5]. In general, the distributed generation/micro-sources are nonconventional/renewable DERs driven by different arrangements of adjustable prime movers. As to permit micro-sources operation to adjustable manner, energy storing equipment is assigned through the load management, utilizing their individual Micro-source Controllers (MCs). Power electronicbased MS supervisors perform required local controls of the energy storing devices and MS which is useful in safeguarding the power quality and energy equilibrium in the network $[1,6]$. A microgrid connects to the electrical power grid at a Point of Common Coupling (PCC), where frequency and voltage of microgrid is as same as power grid. Microgrids that do not have a point of common coupling are treated as stand-alone/isolated/islanded microgrid. In general a microgrid can work in either stand-alone or grid connected mode, any disturbance occurs in main grid, it turns into standalone/islanded mode by the action of a fast acting Static Switch (SS) for improvement of supply reliability to consumer [7, 8]. Fault current levels in microgrid systems are increasing because of the rise in interconnection of distributed generation which is expected to continue in future which might be a revolution [9]. In general microgrid is classified into 3 categories. They are LV microgrid = $1 \mathrm{KV}$, MV microgrid (1-69 KV), HV microgrid $(>69 \mathrm{KV})[10]$. 
There are various types of microgrid with different control strategies, capacities \& architectures. In general microgrid classified into AC, DC \& hybrid microgrid on the basis of system structure, depending on the kind of micro source used, micro sources may be generating DC power or AC power [11]. The power produced is converted to DC in case of AC power. Voltage Source Inverter (VSI) supplies DC power to main grid which is controlled by Pulse Width Modulation (PWM) technique. The output voltage and the angle of the VSI can be governed by PWM. An inductor is used to integrate the output of the VSI to PCC. The phase angle \& voltage at VSI, reactance provided by inductor and the phase angle \& voltage at PCC decides the reactive and real power flow to utility grid from micro source [4]. DC and $\mathrm{AC}$ microgrid can further be divided into three types, fully renewable, partially renewable and completely conventional based on DG sources. Both $\mathrm{DC}$ and $\mathrm{AC}$ systems can have energy storage system incorporated [12]. In spite of many advantages of microgrid, there are few key challenges to connecting microgrid to power grid. These challenges can be categorized as technical challenges related with control and protection system, regulation challenges and consumer participation challenges. Regulation challenges are related to microgrid legality, regulation policies and engagement between microgrid customers and firms, technical challenges related to interconnection of renewable sources and issues associated with that, protection issues with the renewable sources interconnection as well as operation constraints [13].

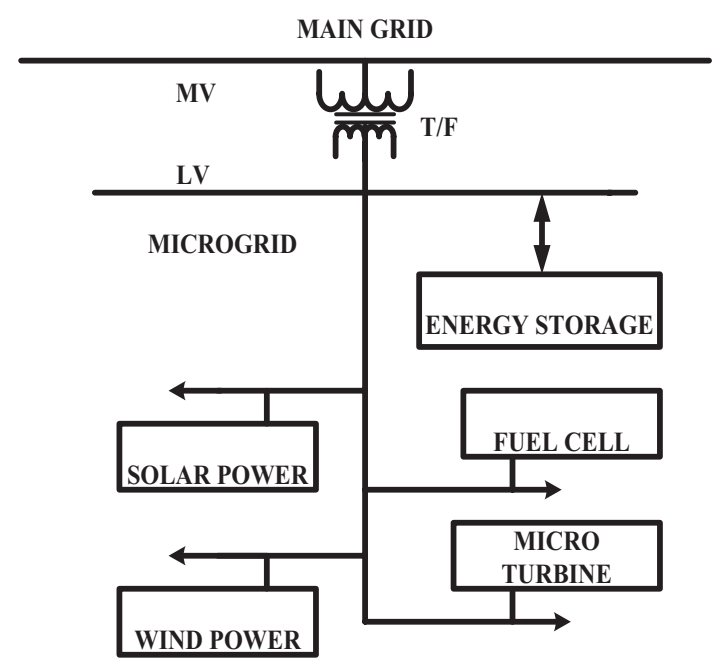

Figure 1 Microgrid Single Line Diagram [1]. 


\section{Microgrid Challenges}

Despite of various advantages provided by microgrid, there are some technical tasks, which need to be met for the researchers. They are bidirectional power flow, stability issues, power quality, low inertia of generators, energy management, uncertainty load profile, protection etc. [14, 15].

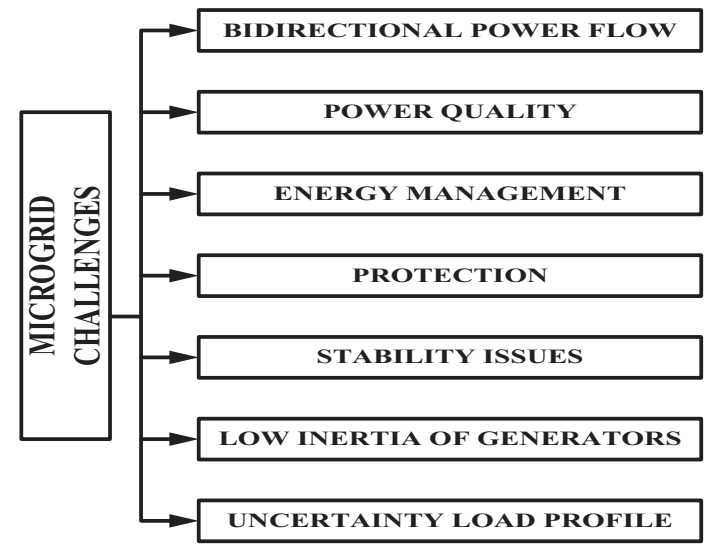

Figure 2 Microgrid challenges.

\subsection{Bidirectional Power Flow}

Power flow within the microgrid is bidirectional, because of various DG connections located at different areas or its mesh architecture which creates critical tasks for the safety of the microgrid [16]. The bidirectional flow of fault currents makes the protection coordination complex, as fault current fluctuates with the integration of Distribution Generations. Conventional overcurrent protection is considered for radial distribution systems with unidirectional fault current flow and they are no more suitable for stand-alone mode [17].

\subsection{Stability Issues}

For the strength of a MG to provide a smooth changeover from grid connected mode to stand-alone mode requires quick and exact islanding detection. It is the key issue since a failure in islanding detection can spoil loads and generators. For detecting anti-islanding and islanding problems different strategies are suggested in the literature. Isolated mode is always in the islanded condition where a MG is at a faraway which has no link with the main power grid. 
This mode has related concerns as islanded mode. Due to little inertia, in case of power instability frequency may deviate due to quick reflection. Detection of high-speed frequency is essential to overcome this situation.

Better performance can be delivered due to tracking ability of modification of high frequency [18].

\subsection{Power Quality}

Power quality (PQ) is a major problem in microgrid system. As the nonconventional/renewable DG sources are extremely dependable on nature, inconsistent behavior of the reserve presents some power quality difficulties. Because of this reason PQ performance for any microgrid system is essential [6]. At last, the power quality challenges in MGs can be listed as:

- The power electronic switches and inverters produce harmonics.

- The intermittent behavior of the wind turbines and photovoltaic cells, and other distributed generators causes voltage flicker and fluctuation.

- The asymmetry of nonlinear loads generates Negative-sequence currents [18].

\subsection{Low Inertia of Generators}

Microgrid utilizes small range generators with less inertia that are usually equipped with Power Electronic Interfaces (PEI) in resistive networks, while the power grid comprises huge synchronous machines with inductive network and high inertias. The power electronic interfaces embedded in microgrid are fast, which enable a full control of system transients by presenting virtual inertia employed through control loops known as microgrid droops. The implementation of droops enables certain adjustments in voltage and frequency that are in proportion to reactive and real power at converter terminals [19]. Low-inertia is significant issue for microgrid. The nature of an MG with low-inertia is unlike from conventional power systems. Existing power systems have the chance to store energy on revolving synchronous generators. But, during islanded mode few type of energy storages are required to deal with transients in MGs. An effective frequency control process stresses storage strategies and load shedding as the inertia in a MG is low. The frequency deviation and rate of change of speed is inversely proportional to inertia. Power grids can keep voltage and frequency at troubles by the control and large inertia of synchronous generators. A huge amount of kinetic energy is stored by synchronous generators in their inertia rotors which are 
high. In islanded mode, the low-inertia can led to more frequency fluctuations if some proper devices for controlling are not applied for power distribution resolutions [18].

\subsection{Energy Management}

So far the various functions are explained where a microgrid comprises of energy management system. This arrangement requires several devices which are maintained to serve towards a definite goal. Energy management system essentially consists of three hierarchical levels of control [12]. The microgrid and the outside world are controlled by Micro-Grid Central Controller (MGCC). MGCC communicates with Market Operator (MO) and Distribution Network Operator (DNO) and improves operation of the microgrid through Local Controllers (LCs).

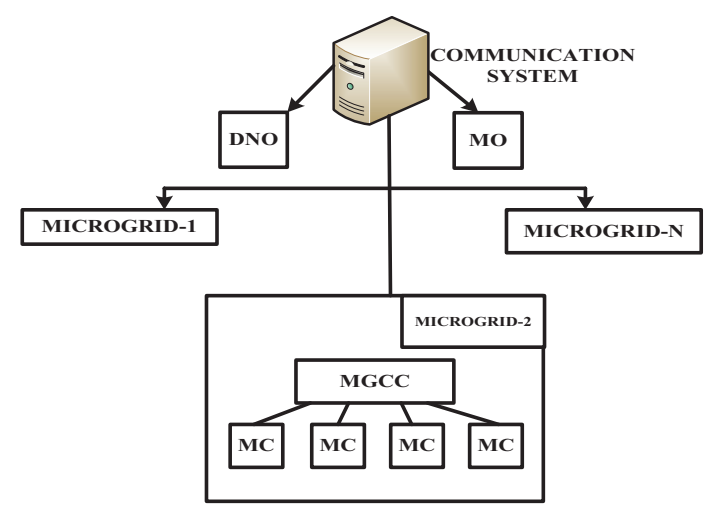

Figure 3 Control levels of the Microgrid.

\subsection{Uncertainty Load Profile}

More uncertainties will be challenged when compared with the conventional power systems in the generation development of a microgrid due to less precision in the calculation of small-scale load demands and un-deployable energies. Recently, some scholars have considered the problems about the generation forecasting of microgrid considering forecasting uncertainties. Their works can be characterized into stochastic optimization, fuzzy optimization, interval optimization and robust optimization [20]. 


\subsection{Protection}

In general, DGs interfaced to a microgrid are irregular in producing power since they are nature dependent (like wind, photovoltaic based DGs). So, microgrid experiences several fault current levels, dependent on the active DG connections [16]. Differential current protection needs a suitable communication channel for sudden data transfer between the terminals of the protected element. Due to the chances of loss of data or possible communication failure, differential protection will need a distinct backup safety method which increases the total size and cost of the safety method to limit its utilization in microgrid. The main protection problem related with microgrid is that the fault currents are low in islanding mode than in the grid-connected mode [21]. In [22] author proposed non-unit protection method for DC microgrid based on measurements within the DC microgrid. The proposed method is based on DC current natural characteristics and under faulty conditions, its first and second derivatives are considered. The communication delay is avoided because of local measurements and faults are detected $\&$ discriminated by the appropriate protection method within microseconds of its initiation. The quicker operation of protection scheme progresses the capability to retain synchronism after transformation to islanded operation, which is important in the view of stability [23]. In [24] author proposed a scheme which has the potential to shelter radial and looped microgrids against several types of faults with the ability of single-phase tripping. Further, since Microprocessor Based Relays (MBR) are able of updating their pickup values (equivalent positive-sequence impedance in downstream and upstream of each line) after the first change in the micro-grid configuration (such as transferring to islanded

from grid-connected mode and or disconnection of a line, DER or bus either in islanded or grid-connected mode), they can protect buses and micro-grid lines against successive faults. In [25], an efficient method for management of separate protection schemes is offered to ensure the operation of a microgrid system. The technique first starts with synchronization of overcurrent (OC) relays and followed by directional overcurrent (DOC) relays in the system. If the coordination of these two types of relays is insufficient, then differential (DIF) relays are utilized to change the OC relay in the damaged division. The suggested technique takes equipment sensitivity, proper protection function and selectivity instantaneously into account. Simulation results show that the suggested synchronization technique safely protects the microgrid system during both islanded and grid-connected operating methods. 


\section{Microgrid Protection Methods}

The microgrid protection techniques available in the literature are discussed on the basis of local measurements, communication systems utilized or by the utilization of devices being used externally. The protection problem is solved with the help of communication methods. By adjusting relay settings automatically, this problem is solved using online communication systems. A communication setup is used broadly in an adaptive way for updating relay settings. A CPU is also added in extension to previous communication setup. The differential relays settings are proposed by a strategy in differential protection. The relays used are communication-assisted. The local measurements detect the fault event in overcurrent protection, the inter breaker communication clears it. The supervisory controller is used to update the relay settings. The disadvantage is that the configurations possible in the microgrid should be known before the protection is implemented. The new types of relays use other methods in local measurements without utilizing communication. The fault is recognized by the voltage magnitude.

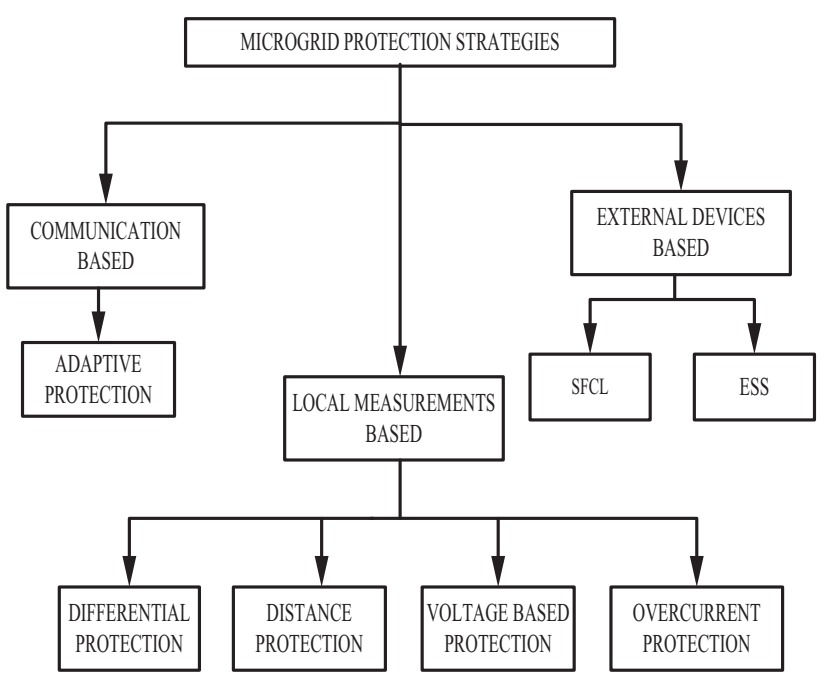

Figure 4 Microgrid Protection Strategies.

The synchronized phasor measurement principles are utilized for the current measurement. The line admittance is used for the calculation of the distance from fault to change relay settings without any help of communication. The digital relays coordination on the basis of wavelet packet transform us utilized for the detection and clearing of the fault. At last, there are methods 
that suggest the devices used externally such as fault current limiters and energy storage systems with high fault current capability (e.g., flywheels) are expensive solutions for the protection [26]. In a microgrid, the operating principle is that in ordinary situation, microgrid would work in grid-connected mode. But, it disconnects from the effectiveness at the PCC and continues to work as stand-alone if there is any fault in the utility. The protection methods are divided into three categories mainly which are the methods for only islanded, for only grid-connected and for both grid-connected and islanded modes.

\subsection{Adaptive Protection}

The contrast within the fault currents in islanded modes and grid-connected systems might require adaptive protection schemes in microgrids. Adaptive schemes include two types of settings in relay, one for islanded mode and other for grid-connected systems. Relays might select settings properly when microgrid switches into different modes of operation. In islanded mode, the performance curve of Time-OC (TOC) relay will be moved to instantaneous and/or definite-time OC settings to get used to minimize fault currents. Also, adaptive protection methods might automatically vary the settings of relay as per network operating state. For example, voltage restraint OC protection method might decrease relays time dials (tripping delays) in case of large depressions in voltage [27]. MG protection is a task importantly due to regular re-setup of the network at the distribution. The conventional protection methods are not appropriate for networks used for MG which demands a relay setup protection method to confine the part of network which is faulty in minimum period of time. In this paper, mentioned demand is desired to meet using a $\mathrm{CPC}$ whose functions comprise MG monitoring continuously, identification of branch identification faulted and fault occurrence. The suggested Primsaided Dijkstra set of rules are executed always at the CPC for facilitating present shortest pathway identification and topology identification between the nearest working source and faulted point in MG. The suggested algorithm helps the CPC in changing the settings of the relay for attaining clearance of the fault in short time with network disconnection in minimum in the shortest pathway based on different selectivity levels. The suggested algorithm is tested efficiently and authenticated on the standard 40-bus MG and reconfigurable IEEE 21-bus networks [28]. Hengwei Lin, Joseph M. Guerrero an adaptive overcurrent protection method established on measurement of synchronous phase is suggested to operate in various modes in microgrid [29]. In [30] Hari 
Krishna Muda, Premalata Jena proposed an adaptive directional overcurrent relaying method based on the negative-sequence (NSQ) and positive-sequence (PSQ) superimposed currents is suggested to safeguard the microgrid. Due to the revolution in operation of microgrid in various modes, the direction and level of pre-fault current are changed. In [31], Hannu Laaksonen, Dmitry Ishchenko demonstrates the requirements for aspects of design of the adaptive protection method pointing issues like: selection of components, alternative setting clusters and system configuration; programmed logic and system architecture. The system is based on a centralized supervisor running and shared by means of IEC 61850 communications; the real-time analysis of the data is acknowledged from the field Intelligent Electronic Devices. The microgrid control scheme and adaptive protection is mounted at Hailuoto Island in Finland and has been developed.

\section{Drawbacks:}

- Calculation of short-circuit current is difficult for microgrid with different operating approaches.

- Functioning and design of microgrid is to be known to implement adaptive schemes.

- Upgradation or updating in power system is required for the protection equipment.

- Expensive for establishment of installation of a communication system.

\subsection{Differential Protection}

Differential protection relates the currents that leave and enter a protected region and work when differential between these currents surpasses predetermined value. Based on differential protection, a different method was forwarded by Dewadasa et al. [16] in 2011. This method takes the protection tasks into account like reduction of fault current level and bidirectional power flow in the islanded mode of operation and can prevent the microgrid both in grid-connected systems and in island operation modes. One of the types of the scheme is not only protects the feeder but also protects the DG sources and buses in microgrid [32]. A collective method for microgrid protection by symmetrical component calculations and differential protection is proposed by Nikkhajoei and Lasseter [33]. They used negative sequence and zero sequence currents within the microgrid for the detection of Single Line-toGround (SLG) and Line-to-Line (LL) faults, respectively. Zeineldin et al. [34] discussed the forthcoming of microgrids and are discussed on important 
tasks namely, protection and voltage/frequency control. Accordingly, they developed a method where differential relays are used in both the ends of every line where the relays are intended for operation in $50 \mathrm{~ms}$. These relays were able of protect the microgrid in both modes i.e., autonomous and grid-connected operation modes.

\section{Drawbacks:}

- It is required for a secondary protection method for the communication system that may not respond or fail.

- Expensive to start a communication infrastructure.

- Problems arising in unbalanced loads or systems.

- Transients during disconnection and connection of DGs which cause difficulties.

\subsection{Distance Protection}

The transmission line impedance is directly proportional to the length of the line which is required to utilize relay that measures the impedance of line till the pre-assumed point for the measurement of the distance. These types of relays are called distance relays and are intended to work for faults that occur between selected reach point and the location of the relay.

Arindam Ghosh, Manjula Dewadasa and Gerard Ledwich proposed a relay based on inverse time admittance for radial distribution system incorporating several C-DGs [35]. The proposed method can be met during detecting of fault currents with lesser values. This method firstly obtains normalized admittance which is used to find the characteristic of an inverse time tripping. The relay trips only when the measured admittance more than total admittance line segment which is to be protected, or normalized admittance becomes more than 1.0. In the suggested method, every relay has two different zones for protection which are Zone- 1 and Zone- 2 and in that zone value of admittance depends on distinct inverse time characteristic. Thus, each relay in the upstream offers standby for the next relay in the downstream. To differentiate between reverse and forward faults this method suggests the use of directional feature. Also, to sense more impedance/resistance faults, Zone-3, the third zone for each relay is presented. Tripping characteristics of relays are reverse faults and the forward faults. Dewadasa $[14,35]$ has established the main technique in this group with characteristics of inverse time tripping based on an admittance relay. The relay is able to isolate and distinguish the faults in autonomous and grid-connected microgrid. 
Arindam Ghosh, J. Manjula Dewadasa and Gerard Ledwich presented a distance protection scheme in [36] for microgrid with C-DGs. The performance of distance relays has been predicted with Mho characteristic for unbalanced (LG, LL, LLG) faults in a radial feeder system using MATLAB calculations and PSCAD simulations. A converter control technique is suggested to fix the current of the controller by keeping the voltage of healthy phases unchanged and by decreasing the voltage in the faulty phase(s). The effects of load and fault resistance is measured on Mho characteristic which has been observed that the relay downstream to the fault operates unreasonably for ground faults when little fault impedance appears at fault point and star-connected load is connected downstream to fault. To ease this problem, the distance relay has been added with directional feature which has been introduced. To resolve the same difficulty, at each distance relay location the analysis of negative sequence impedance has been done [37] by Arindam Ghosh, Manjula Dewadasa and Gerard Ledwich. The negative sequence impedance reactive part is found to be used to differentiate forward and reverse faults efficiently for radial networks with C-DGs.

\section{Drawbacks:}

- Because of transient nature of harmonics and current problems may be arising in accuracy.

- Due to fault resistance, errors in the measured admittance might be generated.

- In short lines, measuring of admittance in distribution networks are difficult.

\subsection{Voltage Based Protection}

The voltage based protection studies are generally are based on monitoring output voltages of DG resources and transforming them from the abc-axis into the direct-quadrature $(\mathrm{d}-\mathrm{q})$ axis in order to reduce the calculation and complexity. Thus the transformation of abc axis to the $\mathrm{d}-\mathrm{q}$ transformation generates the DC equivalent values for three-phase system which in turn reduces the three variable quantities into two DC quantities to reduce calculations. The basic principle of fault detection using voltage method is to analyze the observed parameters in $\mathrm{d}-\mathrm{q}$ axis which is then compared to the reference value in order to calculate the distorted signal $\left(\mathrm{V}_{\text {DIST }}\right)$. In normal condition, the value of the distorted signal should be zero. If $\mathrm{V}_{\text {DIST }}$ is equal to a DC value, then the fault is of the three-phase type. If the value of the 
$\mathrm{V}_{\text {DIST }}$ equals a DC value with an AC ripple, then the fault is two-phase. In case of single phase fault, the $\mathrm{V}_{\text {DIST }}$ is an oscillatory value, varying from zero up to a maximum. The calculated value of $\mathrm{V}_{\text {DIST }}$ is used to locate the fault location. If $\mathrm{V}_{\text {DIST }}$ exceeded threshold value in a bus, the bus will be introduced as faulted bus [38]. In [39] M.A. Redfern and H. Al-Nasseri suggested a novel relay which uses fluctuations in 3- $\phi$ voltages to offer fast detection and reliable of various types of faults existing in the microgrid. To detect the fault and to identify its type and for initiating the isolation of the faulted part and to provide disturbance signal, the algorithm uses the d-q reference frame. After various stages of improvement, suggested monitoring the micro source output voltages, converting the measured signals to DC quantities from the $\mathrm{ABC}$ operating frame in two steps in the dq frame to differentiate between out-of-zone and in-zone faults where a communication link is used within the relays. Moreover this, method is finished developing a decision-making method for the contrast in each relay between average voltage values. Randomly in [40], the authors too suggested to use the total harmonic distortion (THD) for improvement in microgrid for the protection system with inverter-interfaced micro sources, for ground faults. As per the standards of IEEE THD is less than 5\%. Later recognizing the type of fault by observing the change in fundamental frequency $(50 \mathrm{~Hz})$, voltage threshold of relays of different feeder are analyzed to determine fault affected zone. Instead of using voltage magnitude and to prevent the difficulty of previous techniques were related by detection of oscillation waveform of the voltage variation. T. Loix et al. [41] claims that a difference within the three fault types can be made only by considering inverse and direct voltage components. Moreover, the authors also suggested a microgrid protection strategy in terms of current and voltage based on measurement of the faults.

X-P. Wang et al proposed a methodology to find the fault zone and the fault occurrence, based on its subsequent transformation to dq coordinates from $\mathrm{ABC}$ coordinates and a bus bar voltage measurement [42].

\section{Drawbacks:}

- Voltage in the microgrid drop results in disoperation of protection devices.

- High Impedance Faults cannot be identified by using voltage based protection.

- Most of these methods are tested and designed for particular microgrid. As a matter, they depend strongly on the protection zone definition and 
configuration of the microgrid. Therefore, they might not be suitable for microgrid with various structures.

- Less sensitivity is being present in the power grid interconnected operating mode.

\subsection{Deployment of External Devices (FCL, ESS)}

\subsubsection{Fault current limiter (FCL)}

A fault current limiter (FCL) is equipment with small impedance in normal working condition, turn to the state of huge impedance if the current exceeds a given threshold limit due to a fault. Such a component is capable to raise the short circuit power of system in minimal condition without threat for equipment in the case of fault [43]. FCL is a basic element for future smart grids due to the above mentioned reason. Its overview in the power system brings about several benefits which are:

- Permits an abnormal state of systems interconnecting along these lines making conceivable a flexible connection between generation units, operators at distribution side and customers which is necessary in the present day electric power market.

- Integration of distributed generation is possible with main grid (Also from sources which are non-programmable such as non-conventional energy sources).

- Permits a higher power quality in terms of voltage by reducing harmonics, sags, interruptions and flickers.

- In case of network expansion, FCL prevents the need of upgrading the protecting equipment.

\subsubsection{FCL Challenges}

The most projecting task in utilizing protection in FCL-based methods in terms of calculating the FCL impedance value, where it is a problem to determine for microgrid with extensive expansion of DGs due to the common effect in DGs. Additionally, FCL transient response becomes a big problem [1].

\subsubsection{Classification of FCL}

The modern technologies and new materials in the last three decades have utilized to make equipment with appropriate constraints. Hence, the commonly used classification of FCLs is: 
Table 1 Characteristic required for FCLs [46]

\begin{tabular}{|c|c|}
\hline Characteristic & Illustration \\
\hline Negligible line impedance & $\begin{array}{l}\text { - Introduces negligible series impedance on a } \\
\text { system during healthy operating conditions }\end{array}$ \\
\hline Rapid response & $\begin{array}{l}\text { - Minimize the fault current to below thresholds in } \\
\text { quick time. }\end{array}$ \\
\hline $\begin{array}{l}\text { Recognition between fault } \\
\text { and over-current existing } \\
\text { temporarily }\end{array}$ & $\begin{array}{l}\text { - To recognize the difference between } \\
\text { the cover-current existing temporarily and actual } \\
\text { fault. } \\
\text { - Over-current existing temporarily may be due to } \\
\text { overload, a state where it is not required to limit } \\
\text { the fault current to occur. }\end{array}$ \\
\hline $\begin{array}{l}\text { Permitting of some current to } \\
\text { follow }\end{array}$ & $\begin{array}{l}\text { - Enough amount of current is to be allowed to the } \\
\text { protection scheme to control the fault current } \\
\text { which can be within the range in the prescribed } \\
\text { limits. } \\
\text { - If the fault is not sensed by the protective relay, } \\
\text { then FCL must limit the current below the sensing } \\
\text { thresholds and the FCL will be necessary to hold } \\
\text { the fault current for more period of time even } \\
\text { when the time period extends. }\end{array}$ \\
\hline $\begin{array}{l}\text { Maintains increase in voltage } \\
\text { within operating range }\end{array}$ & $\begin{array}{l}\text { - As the resistance increases, the voltage on fault } \\
\text { current limiter will increase during a fault. } \\
\text { - An FCL must be able to work without the increase } \\
\text { in voltage to levels more than the electrical } \\
\text { insulation ratings. }\end{array}$ \\
\hline Instant recovery & $\begin{array}{l}\text { - After clearing the fault, the FCL is instantly able } \\
\text { to regain its initial state when the network is } \\
\text { restored. }\end{array}$ \\
\hline Redundancy & $\begin{array}{l}\text { - If primary control mechanism is unsuccessful, } \\
\text { fault current limiter can able to provide some } \\
\text { controlling capability via its back-up protection. } \\
\text { - If fault current limiter is unsuccessful to limit, } \\
\text { then circuit breakers and other equipment can be } \\
\text { destroy. }\end{array}$ \\
\hline
\end{tabular}

\section{Non-superconducting FCL}

The various types of FCLs designed are:

\section{a. Saturable core FCL}

They exploit the non-linear behavior of ferromagnetic materials to realize more inductance (Figure 5). In general case, the core is saturated by a bias current where the coil inductance is negligible. If the fault occurs, the magnetic 
core is taken out of saturation, limits fault current and the coil attains a high inductance. The designs differ in the core bias, core shape arrangement and magnetic design [44]. They exploit the non-linear behavior of ferromagnetic materials to realize more inductance (Figure 5). In general case, the core is saturated by a bias current where the coil.

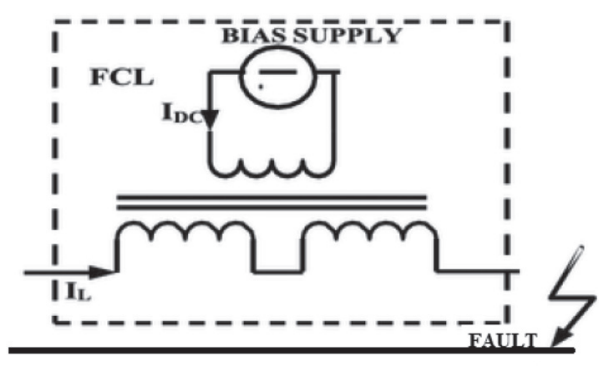

Figure 5 Saturable core FCL.

\section{b. Solid-State FCL}

They use the high-power semiconductor devices - SCR, GTO, and IGBT to realize a FCL. The solid-state FCL could be classified into three main groups: The serial types FCLs are composed of bypass circuit along with bidirectional controlled switch (Figure 6). The bypass circuit consists of fault current bypass, normal state bypass, over voltage protection bypass and snubber. The normal state bypass usually is an electromechanical switch. Its purpose is to reduce the distortion and losses in the normal state. The fault current bypass restricts the fault current - some methods turn off the switches to modulate the fault current to keep it within the acceptable limits and the other interrupts the current. The over voltage protection bypass and the snubber are important as they control the voltage and dv/dt across the semiconductor switch and energy stored in the inductance is absorbed to some amount [44].

\section{c. The bridge type FCLs}

They are recognized by utilizing a current-fed thyristors/diodes full bridge arrangement (Figure 7). The current rating of thyristors/diodes and the limiting reactor are presented by the fault current of the rectifier at the peak level as on the DC side, the current limiting reactor is present and during the fault conditions the inductor is subjected to high DC voltage which may cause saturation of the inductor and FCL may lose the limiting of current and its capabilities and the current increases very fast. Another disadvantage of these devices is an important conduction loss in normal state operation [44]. 


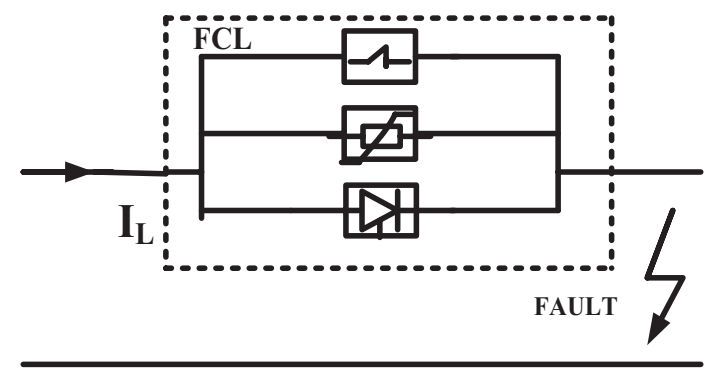

Figure 6 Series type solid state FCL.

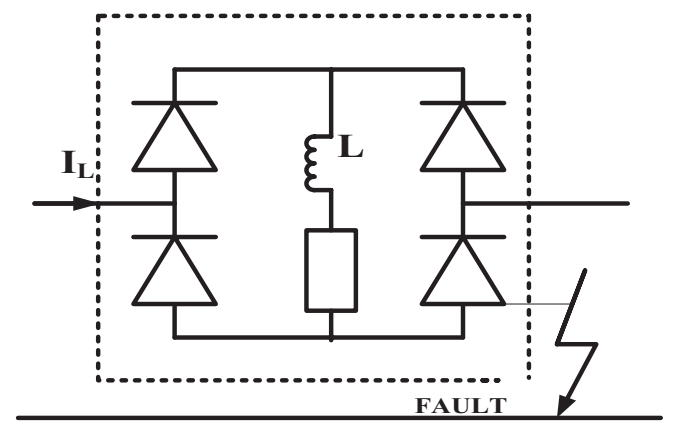

Figure 7 Bridge type solid state FCL.

\section{d. The resonance type FCLs}

They use switches to re-setup their methods either into the fault condition or normal state (Figure 8). They use series resonant circuit which is tuned to line frequency and finally, present impedance to line which is negligible. Under the fault conditions the circuit is switched to fault state sub-topology and much higher impedance is offered to line. The resonance FCLs does not have interruption capability as they reduce the fault current [44, 45].

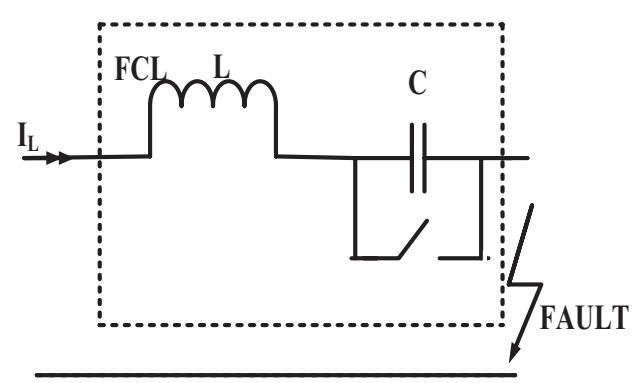

Figure 8 Resonant type solid state FCL. 


\subsubsection{Fault current limitation level of FCLs}

\section{a. Heavy Limitation Mode}

In this mode, the FCL impedance is generally greater than half of the rated impedance of the load [47]. After transient, fault current is restricted under rated current. The role of fault current reduces for the increase in FCL impedance. The essential resistive FCLs impedance and inductive FCLs are presented in Equation (1).

$$
\begin{gathered}
X_{F C L}>\left\{\begin{array}{l}
\frac{V_{\text {rated }}}{2 I_{\text {rated }}}, \text { resistive } \\
\frac{\sqrt{3} V_{\text {rated }}}{2 I_{\text {rated }}}, \text { inductive } F C L
\end{array}\right. \\
X_{F C L}<\left\{\begin{array}{l}
\frac{V_{\text {rated }}}{2 I_{\text {rated }}}, \text { resistive } F C L \\
\frac{\sqrt{3} V_{\text {rated }}}{2 I_{\text {rated }}}, \text { inductive } F C L
\end{array}\right.
\end{gathered}
$$

Where XFCL is FCL impedance during limitation mode, $\mathrm{I}_{\text {rated }}$ is rms rated current and $\mathrm{V}_{\text {rated }}$ is rms rated voltage of the system.

\section{b. Light Limitation Mode}

In this mode, FCL impedance is generally lesser than half of the rated impedance of the load [47]. The action of circuit breakers is maintained such that limited fault current is more than twice the rated current. The impedance required for inductive FCLs and resistive FCLs are shown in Equation (2). The FCL power rating is presented as Equation (3). In heavy limitation mode, FCL has lesser power rating which is being observed. Due to the consideration of heat dissipation, inductive FCLs is appropriate to this mode, but resistive FCLs is preferable to heavy limitation mode.

$$
S_{F C L}=\frac{V_{\text {rated }}^{2}}{X_{F C L}}
$$

\subsubsection{Applications of FCL at Microgrid}

A FCL can be established at a node point that joins transmission system to a microgrid for cause of limiting fault currents flowing among them on the occurrence of faults. In General, a transmission system has mesh configuration with the Existing Protection Relay Scheme (EPRS), which must not be changed regularly. The extra fault current given within a microgrid by generation might disorder the EPRS. Due to this, the FCL equipment has high current reduction capability at this location. SSFCL (Si type and SiC type) are 
suitable to fix to a microgrid at the coupling node. During fault, the operation of the microgrid can be islanded when SSFCL functions as a super- fast operating circuit breaker from the microgrid to transmission network to totally cut off current flow. Moreover, for a fault arising in the microgrid, SSFCL can function in phase control mode to permit flow of current to a limited, with the hope that downstream protective equipment would open successively, in the microgrid particularly when the power sources are turned off [47].

\subsubsection{Energy Storage System (ESS)}

High penetration of renewable energy results in fluctuations in the system frequency and causes fluctuations of power flow, which importantly affects the operation of the power system. The situation in microgrid (MG) is worse because of small-time constant of the system [44] and low inertia. Since the level of short circuit in the microgrid is allowed to about 2-3 times of rated current as the existence of energy storage devices, inverter-based DGs, can be utilized to deliver additional level of short-circuit in the network for example batteries and flywheels. Below is the list of some problems linked to utilization of approaches based on supplementary current source [1]

- Significant investments are involved in storage devices

- These strategies are dependent on technology of storage devices' detection of islanded mode and suitable operation.

\subsection{Over Current \& Symmetrical Components}

The overcurrent protection arrangement finds the fault, restricts the magnitude of DER unit output current, and reestablishes the microgrid to the standard operating conditions following to fault clearance. Yazdani, Zamani suggested communication-assisted protection method implemented by commercially existing microprocessor-based relays for the medium-voltage microgrids for protection. Even though established protection method plays a significant role in communications, to reach communication network failures the protection method offers a backup strategy for protection [48]. The article also presents the structure of a relay that allows suggested scheme for protection. Complete simulation studies are accepted to prove the usefulness of the suggested protection scheme under various fault circumstances; in the EMTDC/PSCAD software environment. Amir H. Etemadi, Reza Iravani presented two novel ideas in an islanded microgrid for overloading and overcurrent protection to permit direct voltage control of electronically coupled DER units. The overcurrent protection strategy finds the fault, confines the output current 
magnitude of the DER unit with in its allowable range, and brings back the microgrid to normal working condition following to fault clearance. The overload protection strategy confines the DER unit output power when more power demand is forced [49]. A wide arrangement of time-domain simulation studies in RTDS-based HIL environment and PSCAD/EMTDC platform were accomplished to calculate and validate the feasibility of the suggested methods. One of the most important methodologies was developed by Lasseter and Nikkhajoei [33] in 2006 based on measurements of negative sequence current and zero sequence current for differentiating single L-L and L-G faults respectively.

\section{Drawbacks:}

The need of communication systems is the main problem of most of the protection approaches mentioned above. In such methods, if there is a failure in communication system, coordination of the protection may be endangered.

Table 2 Protection schemes for islanded and grid-connected mode

\begin{tabular}{|c|c|c|c|}
\hline $\begin{array}{l}\text { Type of } \\
\text { Protection }\end{array}$ & Type of Fault & $\begin{array}{l}\text { Approaches } \\
\text { Applied/Functions }\end{array}$ & Advantages/Limitations \\
\hline $\begin{array}{l}\text { Adaptive } \\
\text { protection } \\
{[1,10]}\end{array}$ & LLL, LL, LG & $\begin{array}{l}\text { Directional interlocking } \\
\text { capability for numerical } \\
\text { directional-OC relays. }\end{array}$ & $\begin{array}{l}\text { Simulation results only for } \\
\text { HIF, D-DGs are not } \\
\text { considered, need } \\
\text { communication, centralized } \\
\text { control is used for } \\
\text { protection settings. High } \\
\text { implementation cost. }\end{array}$ \\
\hline $\begin{array}{l}\text { Differential } \\
\text { protection } \\
{[1,10]}\end{array}$ & LLL, LG & $\begin{array}{l}\text { OC relays and } \\
\text { communication link. }\end{array}$ & $\begin{array}{l}\text { Economical (existing } \\
\text { communication link and } \\
\text { traditional OC relays), but } \\
\text { useless when loads are } \\
\text { unstable. }\end{array}$ \\
\hline $\begin{array}{l}\text { Voltage based } \\
\text { protection } \\
{[1,10]}\end{array}$ & LLL, LL, LG & $\begin{array}{l}\text { DGs output voltages } \\
\text { transformation from abc } \\
\text { to dq frame. } \\
\text { Communication link } \\
\text { between relays. }\end{array}$ & $\begin{array}{l}\text { Trip decision depends on } \\
\text { communication channel. } \\
\text { High impedance faults and } \\
\text { single-pole tripping are not } \\
\text { considered. }\end{array}$ \\
\hline $\begin{array}{l}\text { Residual } \\
\text { current and } \\
\text { symmetrical } \\
\text { component } \\
\text { based system } \\
{[1,10]}\end{array}$ & LG, LL & $\begin{array}{l}\text { OC relays, zoning } \\
\text { principle, static switch at } \\
\text { PCC. }\end{array}$ & $\begin{array}{l}\text { Delivers full protection } \\
\text { from LG and LL faults. No } \\
\text { use of communication } \\
\text { channel. But, three phase } \\
\text { and high impedance faults } \\
\text { and single pole tripping are } \\
\text { not considered. }\end{array}$ \\
\hline
\end{tabular}




\section{Superconducting Fault Current Limiters}

These limiters are an innovative, precious tool for building the advanced type grid structure as they allow effective utilization of existing grid structures as well as improving the grid stability and power quality [50]. SFCL may reduce the expenditure of transmission line and plant capacities expansion. This limiter offers an efficient way to overpower fault current limiting characteristic of these superconductors depending on their non-linear features with magnetic field, current and temperature fluctuations. The change of superconducting state to normal state exists if there is any rise in anyone of these three parameters [51]. Grid connected microgrids without adding together the shortcircuit currents is provided by the protection of SFCLs [52]. The increasing fault currents is increasing the potentiality of the microgrid to meet the increasing demands which will essentially necessitate replacing a bulk amount of present equipment in power systems, for example relays, circuit breakers and transformers. Superconducting fault current limiter (SFCL) with different design concepts is one of the best optimistic results to avoid the increase in the fault current [53].

Electric current is carried by a superconductor with negligible resistance providing that the magnetic field on it, current density and temperature are all under a critical value. If any of the quantities overcome extreme value superconductor to satisfy to a dissipative state. Superconducting cables are existing in form of tapes or composite conductors which can be used in power application [54]. The features of the identified superconducting fault current limiter are as follows $[55,56]$ :

- Loss is less during healthy operating conditions.

- Faster Response.

- Increase of dynamic stability.

- External control is not required.

- Limit the fault current.

Operation of the Superconducting Fault Current Limiter can be described by three stages:

- The superconductor behaviors current under normal operating conditions as at the SFCL; the line sees virtually zero impedance.

- The superconductor unit becomes extremely resistive, causing current to change to the reactor when fault occurs where increase in impedance lowers the fault current.

- A fast-operating switch eliminates superconductor unit from circuit after current transitions to the reactor [46]. 
Superconducting FCLs are evolving as a new class of equipment that can allow new and unconventional proposal of power utility schemes which becomes most important as the deregulation environment takes hold and uses look for more effective and cost-efficient schemes to couple grids, delay expensive upgrades and improve power quality. As inexpensive HTS materials become available, it should accelerate and be more reliable [57]. The current limiting behavior of SFCL is dependent on nonlinear response of superconducting materials to magnetic fields, current and temperature. A change between normal (resistive) conducting and superconducting modes exists due to the increase of any of the three parameters [58]. SFCLs mainly are of four categories:

\subsection{Resistive Type SFCL}

The resistive type SFCLs is in line with load and source as shown in Figure 9. During the operation in normal state, the superconducting element $\mathrm{R}_{\mathrm{SC}}$ dissipates low energy as the current flows through it. If the current increase is above critical current value the resistance $\mathrm{R}_{\mathrm{SC}}$ rises quickly. The losses dissipated heat the superconductor more than the critical temperature $\mathrm{T}_{\mathrm{C}}$ and the superconductor $\mathrm{R}_{\mathrm{SC}}$ deviates from superconducting state to resistive, some resistance is generated and fault current is minimized and method is called "quench of superconductors". The element $\mathrm{R}_{\mathrm{SC}}$ recovers its superconducting state when the fault current has been reduced. For adjusting the limiting current and for avoiding over voltages because of the limitations of the fast-current, inductive shunt $Z_{\mathrm{SH}}$ or the parallel resistance is required during quench to prevent hot spots. The resistive SFCLs are lighter and smaller than the inductive SFCLs. In the quench state, they are vulnerable to excessive heat [59].

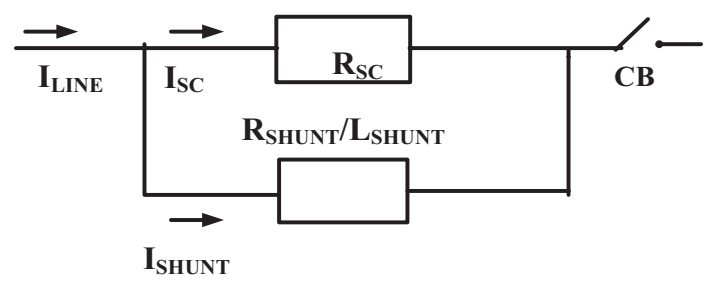

Figure 9 Resistive type SFCL. 


\subsection{Inductive Type SFCL}

The Inductive type SFCL works on the transformer principle which acts as a shorted superconducting secondary winding of transformer where the power system line acts as a primary winding of transformer. The superconductor resistance increases and it transferred into the primary side by $\mathrm{K} 2=(\mathrm{w} 1 / \mathrm{w} 2) 2$ if fault occurs. So, the impedance of line increases in power system. The fault current has been limited by the SFCL (Figure 10.) [46, 60].

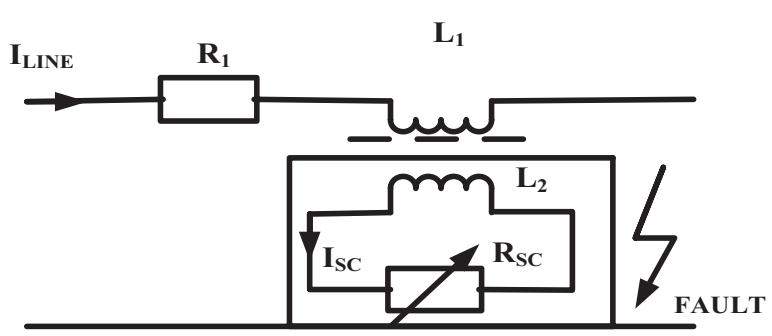

Figure 10 Inductive type SFCL.

\subsection{A Hybrid SFCL}

Hybrid SFCL was previously identified as line-commutated type, the theoretical operation of equipment utilizes High Temperature Superconductor (HTS) only for initiating a fast switch operation. The current being diverted into a reactor, the HTS becomes resistive when the current flows through driving coil as in Figure 11, and fast switch initiates when the field is produced by the coil current. Throughout the remainder of fault event, reactor provides

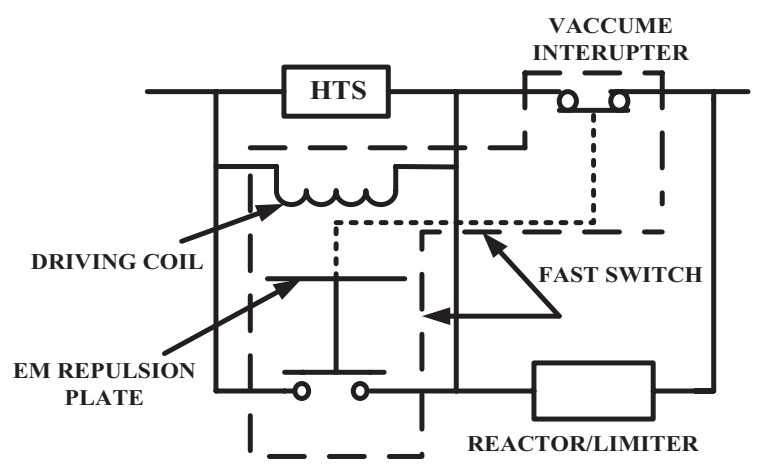

Figure 11 Hybrid SFCL. 
the limitation action. The technique fastly removes the increase in voltage during limiting action from the HTS and over the rest of limiting duration it allows the line reactor to maintain the higher impedance. This idea is beneficial as it decreases the quantity of superconductor and decreases the cryogenic volume, a procedure that permits the equipment to be more solid for substation arrangement. During operation, the fast acting switch is fundamentally a plunger with a switch on either of the ends that tries to commutate line current. The driving coil applies force on repulsion plate to engage and to activate the plunger for limiting reactor [44].

\subsection{Literature Survey}

Maloth Naresh Navneet Kumar Singh described SFCL for the safety of power system which is connected to grid. At various locations of the grid for 3-ph Line- Ground faults, transient analysis is performed. Validation of the usefulness of the equipment in the grid is done without SFCL using transient analysis. Within the power-grid, the optimum location for SFCL installation is recognized with this analysis. The optimum location of SFCL is at combination point of two different power generating stations, for distribution faults and consumer grid [60]. Hyung-Chul Jo, Sung-Kwan Joo suggested a SFCL location technique for power system safety in view of the uncertainty of the DGs. The presented placement of SFCL technique comprising of relay coordination in view of the uncertainty of the DGs and location of SFCL using a minimax regret criterion in [61]. Majid Ebrahimpour, Behrooz Vahidi proposed a Hybrid Superconducting Fault Current Controller (HSFC) utilizes the solid-state and superconducting technologies as to limit the amount of fault current in microgrid and DG networks. The HSFC controller is independent of power grid monitoring technology as it uses the characteristic of HSFC operation. The optimistic value of the SCRs' firing angle will be chosen with respect to the ratio of fault current to critical current of HTS element as the fault current must be kept in particular range to maintain proper coordination between protective devices [62].

Leonard Kowalski, Xing Yuan proposes matrix fault current limiter (MFCL) to discourse at transmission voltage levels of more than $138 \mathrm{KV}$. The MFCL is likely to support transmission utility planers [63]. Teymoor

Ghanbari and Ebrahim Farjah proposed a unidirectional fault current limiter (UFCL) to attain a suitable interface between downstream and upstream. The UFCL acts in the fault condition in the actual network, but, in case of heavy load start up or fault occurrence in downstream, the UFCL is 
deactivated to prevent the above-mentioned problem in the microgrid. Many experiments and simulations are carried out to validate the usefulness of the UFCL [64].

In [65] Feng Zheng, Changhong Deng suggested an R-SFCL to improve the transient performance of a microgrid system through situation of the fault. When short-circuit fault occurs at the connecting line, the SFCL can ease the fault current, and action signal of the SFCL will be sent to the master DG included in the microgrid. From the verified results, utilizing the R-SFCL can efficiently prevent the transient fault current to low level, aid guarantee the microgrid system's power balance, and its voltage and improve frequency stability. Huiwen $\mathrm{He}$, Lei Chen proposes the modified flux coupling-type SFCL to advance inverter interfaced DGs fault ride through capabilities. It studies differential and directional-OC protection for answering to microgrid and islanded grid connected status [7]. In [44] S. B. Naderi, M. Tarafdar Hagh, M. Jafari proposed New Series Resonance Type FCL uses a fast acting switch to place an inductor in combination with a capacitor and arrange resonance condition between them. This arrangement can hold the maximum value of fault current in the constant value which is not attained in a series resonance type fault current limiter.

In [66] Sung-Yul Kim and Jin-O Kim suggested a reliability model for SFCLs in order to exactly assess the consistency of a distribution network where an SFCL is placed. Then, the failure rate of together protective equipment is re estimated, since the decrease in the fault current. Moreover, SAIDI, ENS and SAIFI are recently re-defined when a network comprises of DG which is used to generate electrical energy irregularly. With respect to output of DG, the number of customers are being supplied electrical energy when a fault occurs in a network is being recommended. Based on finite-element method (FEMs), the analysis of electrodynamic forces developed in an inductive SFCL of transformer type [77]. The secondary of the envisaged devices is built by high-temperature superconducting (HTS) coated conductors and distinct configurations (radially and axially distributed windings) are analyzed to determine the most adequate for electromagnetic forces minimization. FEM results for developed axial and radial forces are evaluated and compared, as well as normal magnetic induction and current distribution in each winding. Electrodynamic forces developed under short-circuit events must be well characterized in power-grid applications, as they can compromise the integrity of network systems, particularly power transformers, but also inductive superconducting fault current limiters (SFCLs). These strains can destroy windings causing failure of the devices and affecting power-grid operation. 
Table 3 General characteristics of SFCL [45]

\begin{tabular}{|c|c|c|c|c|c|}
\hline Technology & $\begin{array}{l}\text { Purely } \\
\text { RSFCL }\end{array}$ & $\begin{array}{l}\text { Hybrid } \\
\text { RSFCL }\end{array}$ & $\begin{array}{l}\text { Saturable } \\
\text { Core SFCL }\end{array}$ & $\begin{array}{l}\text { Shielded } \\
\text { Core SFCL }\end{array}$ & $\begin{array}{l}\text { Solid State } \\
\text { SFCL }\end{array}$ \\
\hline Triggering & Passive & $\begin{array}{l}\text { Passive/ } \\
\text { active }\end{array}$ & Passive & Passive & Active \\
\hline Losses & $\begin{array}{l}\text { Hysteretic } \\
\text { (amount is } \\
\text { dependent on } \\
\text { type of HTS } \\
\text { materials) }\end{array}$ & $\begin{array}{l}\text { Hysteretic } \\
\text { (amount is } \\
\text { dependent on } \\
\text { type of HTS } \\
\text { materials) }\end{array}$ & $\begin{array}{l}\text { Joule heating } \\
\text { is essential in } \\
\text { conventional } \\
\text { conductors } \\
\text { and for the } \\
\text { saturation of } \\
\text { iron core DC } \\
\text { power is also } \\
\text { required. }\end{array}$ & $\begin{array}{l}\text { Hysteretic } \\
\text { (amount } \\
\text { depends on } \\
\text { type of } \\
\text { HTS } \\
\text { materials) }\end{array}$ & $\begin{array}{l}\text { Similar to } \\
\text { resistive } \\
\text { type } \\
\text { SFCLs. }\end{array}$ \\
\hline Distortion & $\begin{array}{l}\text { During first } \\
\text { cycle only. }\end{array}$ & $\begin{array}{l}\text { During first } \\
\text { cycle only. }\end{array}$ & $\begin{array}{l}\text { Some caused } \\
\text { due to } \\
\text { non-linear } \\
\text { magnetic } \\
\text { characteristic. }\end{array}$ & $\begin{array}{l}\text { Only } \\
\text { during first } \\
\text { cycle. }\end{array}$ & $\begin{array}{l}\text { Switching } \\
\text { electronics } \\
\text { introduce } \\
\text { harmonics. }\end{array}$ \\
\hline Recovery & $\begin{array}{l}\text { HTS } \\
\text { conductor } \\
\text { essentially be } \\
\text { re-cooled. }\end{array}$ & $\begin{array}{l}\text { Less energy } \\
\text { is deposited } \\
\text { in HTS as its } \\
\text { faster than } \\
\text { purely } \\
\text { resistive. }\end{array}$ & Immediate. & $\begin{array}{l}\text { Re-Cooling } \\
\text { required as } \\
\text { its faster } \\
\text { when } \\
\text { compared } \\
\text { to purely } \\
\text { resistive. }\end{array}$ & Immediate. \\
\hline Size/Weight & $\begin{array}{l}\text { Limiting } \\
\text { action is } \\
\text { performed by } \\
\text { HTS as the } \\
\text { potential is to } \\
\text { be small. }\end{array}$ & $\begin{array}{l}\text { Size of } \\
\text { additional } \\
\text { equipment } \\
\text { increase as } \\
\text { potential is to } \\
\text { be small. }\end{array}$ & $\begin{array}{l}\text { Due to } \\
\text { conventional } \\
\text { windings and } \\
\text { iron core it is } \\
\text { heavy. }\end{array}$ & $\begin{array}{l}\text { Due to } \\
\text { windings } \\
\text { and iron } \\
\text { core it is } \\
\text { heavy. }\end{array}$ & $\begin{array}{l}\text { Similar to } \\
\text { purely } \\
\text { resistive. }\end{array}$ \\
\hline
\end{tabular}

Lei Chen, Feng Zheng proposed an improved flux-coupling type SFCL to improve the transient performance of a distinctive microgrid system. The SFCL is connected at the PCC between microgrid and main network which is likely to dynamically advance the micro grid's fault ride-through capability [68]. Harmonic effects of an innovative solid stated FCLID and a DC reactor type SFCL are differentiated by Mohana.U.M. Based on specified results, in spite of SFCL, presented FCLID meets IEEE 519 harmonic standards and doesn't require filtering [69]. In [70] Jae-Ik Yoo, Dong-Hee Choi analyses the result of a R-SFCL applied to a remote microgrid with an active load model. 
The R-SFCL in islanded microgrid can efficiently moderate the fault current by quickly providing safety during fault and improve the transient stability by utilizing the fast response characteristics of the R-SFCL as a changeover signal for the DG.

Jiahui Zhua, Xiaodong Zhenga describes simulation model for an R-SFCL comprised of YBCO tapes developed using MATLAB/SIMULINK software which is considered for internal electromagnetic behavior of SFCL. The results showed that SFCL is efficient in limiting fault currents with a maximum of half of within the transmission lines [71]. Jeff Moscrop, Scott Hopkins the expansion of an example illustrated saturated core HTS FCL. Through analysis, the performance of this equipment is characterized in terms of fault current limiting ability, steady state performance and DC saturation [72]. In [73] Teymoor Ghanbari and Ebrahim Farjah dealt with advancement of resonant type SSFCL, suitable for DG units in the microgrid. The suggested SSFCL which is adjusted at supply frequency has parallel and series resonant circuits. A model illustrating SSFCL is simulated in the EMTP and tested. The results finally shows that suggested SSFCL can lower than the fault currents in less time.

Table 4 Current limiting performance characteristics of SFCLs [58]

\begin{tabular}{|c|c|c|c|c|}
\hline Characteristic & Resistive SFCL & SSFCL & $\begin{array}{l}\text { Saturated } \\
\text { Iron Core } \\
\text { SFCL }\end{array}$ & DFCL \\
\hline $\begin{array}{l}\text { Maximum } \\
\text { Rating }\end{array}$ & $\begin{array}{l}138 \mathrm{kV} \\
0.9 \mathrm{kA}\end{array}$ & $\begin{array}{l}69 \mathrm{kV}, 3 \mathrm{kA} \\
\text { (Si type) } \\
6 \mathrm{MVA} \\
\text { (SiC type) }\end{array}$ & $\begin{array}{l}13.8 \mathrm{kV} \text {, } \\
1.2 \mathrm{kA} \\
(138 \mathrm{kV} \\
\text { in plan) }\end{array}$ & $\begin{array}{l}9.35 \mathrm{MVA} \\
(12 \mathrm{kV}, \\
0.45 \mathrm{kA})\end{array}$ \\
\hline Reset Time & $10 \mathrm{~ms}$ to $2 \mathrm{~s}$ & Con. & Imm. & $<20 \mathrm{~ms}$ \\
\hline $\begin{array}{l}\text { Activation } \\
\text { Time }\end{array}$ & $<1 / 4$ cycle & $\mu$ s level & Imm. & $<5 \mathrm{~ms}$ \\
\hline $\begin{array}{l}\text { Triggering } \\
\text { Mode }\end{array}$ & Internal & External & Internal & Internal \\
\hline $\begin{array}{l}\text { Current } \\
\text { Reduction }\end{array}$ & $<80 \%$ & Con. & $30 \% \sim 40 \%$ & $85 \%$ \\
\hline Need Cooling? & Required & $\begin{array}{l}\text { Required }(\mathrm{Si}) \\
\text { Not required } \\
(\mathrm{SiC})\end{array}$ & Required & Not required \\
\hline
\end{tabular}

${ }^{*}$ Con. $=$ Controllable; Imm. = Immediately. 


\section{Conclusion}

This paper comprises of extensive review on microgrid protection using SFCL. With the rise in capacity of electric power generation of microgrid has led to rise in fault current levels which exceeds designed short-circuit ratings of the switchgear at the maximum level. So many challenges are faced by the microgrid during its operation, to overcome these challenges; many conventional protective methods are applied for protection of microgrid from excessive fault current. In this paper, traditional protection schemes are analyzed. Fault current limiting technology is explained in detail, various types of fault current limiters, their operating principles, applications are discussed. SFCL general characteristics and current limiting performance characteristics are presented in this paper. The current limiting behavior of SFCL is dependent on nonlinear response of superconducting materials to magnetic fields, current and temperature. Under normal operating conditions of the SFCL; the line sees virtually zero impedance. The superconductor unit becomes extremely resistive, causing current to change to the reactor when fault occurs where increase in impedance lowers the fault current. SFCL is the advanced protective device which limits the fault current safely and in protective manner. Superconducting fault current limiters are an innovative, precious tool for building the advanced type grid structure as they allow effective utilization of existing microgrid structures as well as improving the grid stability and power quality. Thus this review will be useful for further research in the field of grid integration and protection.

\section{References}

[1] Mirsaeidi, S., Said, D. M., Mustafa, M. W., Habibuddin, M. H., and Ghaffari, K. (2014). Progress and problems in micro-grid protection schemes. Renewable and Sustainable Energy Reviews, 37, 834-839.

[2] Sung, B. C., Park, D. K., Park, J. W., and Ko, T. K. (2009). Study on a series resistive SFCL to improve power system transient stability: modeling, simulation, and experimental verification. IEEE transactions on industrial electronics, 56(7), 2412-2419.

[3] Sabzehgar, R. (2015). A review of AC/DC microgrid-developments, technologies, and challenges. In Green Energy and Systems Conference (IGESC), 2015 IEEE (pp. 11-17). IEEE.

[4] Brearley, B. J., and Prabu, R. R. (2017). A review on issues and approaches for microgrid protection. Renewable and Sustainable Energy Reviews, 67, 988-997. 
[5] Laaksonen, H. J. (2010). Protection principles for future microgrids. IEEE Transactions on Power Electronics, 25(12), 2910-2918.

[6] Mariam, L., Basu, M., and Conlon, M. F. (2013). A review of existing microgrid architectures. Journal of Engineering, 2013.

[7] He, H., Chen, L., Yin, T., Cao, Z., Yang, J., Tu, X., and Ren, L. (2016). Application of a SFCL for fault ride-through capability enhancement of DG in a microgrid system and relay protection coordination. IEEE Transactions on Applied Superconductivity, 26(7), 1-8.

[8] Nikkhajoei, H., and Lasseter, R. H. (2007). Microgrid protection. In Power engineering society general meeting, 2007. IEEE (pp. 1-6). IEEE.

[9] Blair, S. M., Booth, C. D., Singh, N. K., Burt, G. M., and Bright, C. G. (2011). Analysis of energy dissipation in resistive superconducting fault-current limiters for optimal power system performance. IEEE Transactions on Applied Superconductivity, 21(4), 3452-3457.

[10] Memon, A. A., and Kauhaniemi, K. (2015). A critical review of AC Microgrid protection issues and available solutions. Electric Power Systems Research, 129, 23-31.

[11] Zhu, X., Han, X. Q., Qin, W. P., and Wang, P. (2015). Past, today and future development of micro-grids in China. Renewable and Sustainable Energy Reviews, 42, 1453-1463.

[12] Ustun, T. S., Ozansoy, C., and Zayegh, A. (2011). Recent developments in microgrids and example cases around the world-A review. Renewable and Sustainable Energy Reviews, 15(8), 4030-4041.

[13] Yoldas, Y., Önen, A., Muyeen, S. M., Vasilakos, A. V., and Alan, Ý. (2017). Enhancing smart grid with microgrids: Challenges and opportunities. Renewable and Sustainable Energy Reviews, 72, 205-214.

[14] Dewadasa, J. M., (2010). 'Protection of distributed generation interfaced networks', Doctoral dissertation, Queensland University of Technology.

[15] Mirsaeidi, S., Said, D. M., Mustafa, M. W., Habibuddin, M. H., and Ghaffari, K. (2014). An analytical literature review of the available techniques for the protection of micro-grids. International Journal of Electrical Power \& Energy Systems, 58, 300-306.

[16] Dewadasa, M., Ghosh, A., and Ledwich, G. (2011). Protection of microgrids using differential relays. In Power Engineering Conference (AUPEC), 2011 21st Australasian Universities (pp. 1-6). IEEE.

[17] Choudhary, N. K., Mohanty, S. R., and Singh, R. K. (2014). A review on microgrid protection. In Electrical Engineering Congress (iEECON), 2014 International (pp. 1-4). IEEE. 
[18] Dag, O., and Mirafzal, B. (2016). On stability of islanded low-inertia microgrids. In Power Systems Conference (PSC), 2016 Clemson University (pp. 1-7). IEEE.

[19] Alabdulwahab, A., and Shahidehpour, M. (2016). Microgrid networking for the monitoring, control and protection of modern power systems. The Electricity Journal, 29(10), 1-7.

[20] Huang, C., Yue, D., Deng, S., and Xie, J. (2017). Optimal scheduling of microgrid with multiple distributed resources using interval optimization. Energies, 10(3), 339.

[21] Akhtar, Z., and Saqib, M. A. (2016). Microgrids formed by renewable energy integration into power grids pose electrical protection challenges. Renewable Energy, 99, 148-157.

[22] Meghwani, A., Srivastava, S. C., and Chakrabarti, S. (2017). A non-unit protection scheme for DC microgrid based on local measurements. IEEE Transactions on Power Delivery, 32(1), 172-181.

[23] Mahmoud, M. S., Rahman, M. S. U., and Fouad, M. S. (2015). Review of microgrid architectures-a system of systems perspective. IET Renewable Power Generation, 9(8), 1064-1078.

[24] Mirsaeidi, S., Said, D. M., Mustafa, M. W., and Habibuddin, M. H. (2015). A protection strategy for micro-grids based on positive-sequence component. IET Renewable Power Generation, 9(6), 600-609.

[25] Haron, A. R., Mohamed, A., and Shareef, H. (2013). Coordination of overcurrent, directional and differential relays for the protection of microgrid system. Procedia Technology, 11, 366-373.

[26] Oureilidis, K. O., and Demoulias, C. S. (2016). A fault clearing method in converter-dominated microgrids with conventional protection means. IEEE Transactions on Power Electronics, 31(6), 4628-4640.

[27] Che, L., Khodayar, M. E., and Shahidehpour, M. (2014). Adaptive Protection System for Microgrids: Protection practices of a functional microgrid system. IEEE Electrification magazine, 2(1), 66-80.

[28] Swathika, O. G., and Hemamalini, S. (2016). Prims aided Dijkstra Algorithm for adaptive protection in microgrids. IEEE Journal of Emerging and Selected Topics in Power Electronics, 4(4), 1279-1286.

[29] Lin, H., Guerrero, J. M., Jia. C., Tan, Z. H., Vasquez, J. C. and Liu. C. (2016). 'Adaptive overcurrent protection for microgrids in extensive distribution systems'. In Industrial Electronics Society, IECON 2016-42nd Annual Conference of the IEEE, (pp. 4042-4047).

[30] Muda, H., and Jena, P. (2017). Superimposed adaptive sequence current based microgrid protection: a new technique. IEEE Transactions on Power Delivery, 32(2), 757-767. 
[31] Laaksonen, H., Ishchenko, D., and Oudalov, A. (2014). Adaptive protection and microgrid control design for Hailuoto Island. IEEE Transactions on Smart Grid, 5(3), 1486-1493.

[32] Abdulwahid, A. H., and Wang, S. (2016). 'Application of Differential Protection Technique of Domestic Solar Photovoltaic Based Microgrid', International Journal of Control and Automation, 9(1) 371-386.

[33] Nikkhajoei, H., and Lasseter, R. H. (2006). Microgrid fault protection based on symmetrical and differential current components. Power System Engineering Research Center, 71-74.

[34] Zeineldin, H. H., El-Saadany, E. F., and Salama, M. M. A. (2006). Distributed generation micro-grid operation: Control and protection. In Power Systems Conference: Advanced Metering, Protection, Control, Communication, and Distributed Resources, 2006. PS'06 (pp. 105-111). IEEE.

[35] Dewadasa, M., Ghosh, A., and Ledwich, G. (2009). 'An inverse time admittance relay for fault detection in distribution networks containing DGs', In TENCON Region 10 Conference, 1-6, IEEE.

[36] Dewadasa, J. M., Ghosh, A., and Ledwich, G. (2008). Distance protection solution for a converter controlled microgrid. In Proceedings of the 15th National Power Systems Conference.

[37] Dewadasa, M., Ghosh, A., and Ledwich, G. (2008). Line protection in inverter supplied networks. In Power Engineering Conference, 2008. AUPEC'08. Australasian Universities (pp. 1-6). IEEE.

[38] Al-Nasseri, H., Redfern, M. A., and Li, F. (2006). A voltage based protection for micro-grids containing power electronic converters. In Power Engineering Society General Meeting, 2006. IEEE (pp. 7-pp). IEEE.

[39] Al-Nasseri, H., and Redfern, M. A. (2007). A new voltage based relay scheme to protect micro-grids dominated by embedded generation using solid state converters. In 19th International Conference Electricity Distribution (pp. 1-4).

[40] Al-Nasseri, H., and Redfern, M. A. (2008). Harmonics content based protection scheme for micro-grids dominated by solid state converters. In Power System Conference, 2008. MEPCON 2008. 12th International Middle-East (pp. 50-56). IEEE.

[41] Loix, T., Wijnhoven, T., and Deconinck, G. (2009). Protection of microgrids with a high penetration of inverter-coupled energy sources. In Integration of Wide-Scale Renewable Resources Into the Power Delivery System, 2009 CIGRE/IEEE PES Joint Symposium (pp. 1-6). IEEE. 
[42] Wang, X. P., Li, Y., and Yu, Y. Y. (2011). Research on the relay protection system for a small laboratory-scale microgrid system. In Industrial Electronics and Applications (ICIEA), 2011 6th IEEE Conference on (pp. 2712-2716). IEEE.

[43] Ustun, T. S., Ozansoy, C., and Zayegh, A. (2011). A central microgrid protection system for networks with fault current limiters. In Environment and Electrical Engineering (EEEIC), 2011 10th International Conference on (pp. 1-4). IEEE.

[44] Smedley, K., and Abravomitz, A. (2011). Development of fault current controller technology. Public Interest Energy Research (PIER) Program Final Project Report. 7-11.

[45] Hagh, M. T., Naderi, S. B., and Jafari, M. (2010). 'New resonance type fault current limiter'. In Power and Energy (PE Con), IEEE International Conference, (pp. 507-511).

[46] Young., M., and Hassenzahl, W. (2009). 'Superconducting fault current limiters: Technology Watch', EPRI, Palo Alto, CA,1017793.

[47] Zhang, Y., and Dougal, R. A. (2010). Specification of fault current limitation level for FCLs in power systems. In IEEE SoutheastCon 2010 (SoutheastCon), Proceedings of the (pp. 246-249). IEEE.

[48] Zamani, M. A., Yazdani, A., and Sidhu, T. S. (2012). A communicationassisted protection strategy for inverter-based medium-voltage microgrids. IEEE Transactions on Smart Grid, 3(4), 2088-2099.

[49] Etemadi, A. H., and Iravani, R. (2013). Overcurrent and overload protection of directly voltage-controlled distributed resources in a microgrid. IEEE Transactions on Industrial Electronics, 60(12), $5629-5638$.

[50] Tixador, P., and Badel, A. (2015). Superconducting fault current limiter optimized design. Physica C: Superconductivity and its Applications, 518, 130-133.

[51] Chaudhari, Pravin S., and kumar Khampariya, P. (2016). 'Review on Superconducting Fault Current Limiter', International Journal of Current Trends in Engineering \& Technology.

[52] Meyer, F. (2011). 'Superconducting fault current limiters in a power plant', Project Management Organisation, Federal Ministry of Economics and Technology (BMWi).

[53] Hong, Z., Sheng, J., Yao, L., Gu, J., and Jin, Z. (2013). The structure performance and recovery time of a $10 \mathrm{kV}$ resistive type superconducting fault current limiter. IEEE Trans. Appl. Supercond., 23(3), 5601304. 
[54] Morandi, A. (2013). State of the art of superconducting fault current limiters and their application to the electric power system. Physica $C$ : Superconductivity, 484, 242-247.

[55] Nagarathna, M, C., Murthy, H. V,, and Shashikumar, R. (2015). 'A review on super conducting fault current limiter (SFCL) in power system'. Int. Journal of Eng. Research and General Science, 3(2).

[56] Sokolovsky, V., Meerovich, V., Vajda, I., and Beilin, V. (2004). Superconducting FCL: design and application. IEEE Transactions on Applied Superconductivity, 14(3), 1990-2000.

[57] Leung, E. M. (2000). Superconducting fault current limiters. IEEE power engineering Review, 20(8), 15-18.

[58] Zhang, Y., and Dougal, R. A. (2012). State of the art of fault current limiters and their applications in smart grid. In Power and Energy Society General Meeting, 2012 IEEE (pp. 1-6). IEEE.

[59] Ganev, G. I., Hinov, K. L., and Karadjov, N. K. (2012). Fault current limiters-principles and application. SIELA 2012.

[60] Naresh, M., Singh, N. K., and Singh, A. K. (2016). 'Superconducting fault current limiter for grid connected power system protection', In International Conference on Industrial Technology (ICIT), (pp. 576-581), IEEE.

[61] Jo, H. C., and Joo, S. K. (2015). Superconducting fault current limiter placement for power system protection using the minimax regret criterion. IEEE Transactions on Applied Superconductivity, 25(3), 1-5.

[62] Ebrahimpour, M., Vahidi, B., and Hosseinian, S. H. (2013). A hybrid superconducting fault current controller for DG networks and microgrids. IEEE Transactions on Applied Superconductivity, 23(5), 56043065604306.

[63] Kovalsky, L., Yuan, X., Tekletsadik, K., Keri, A., Bock, J. and Breuer, F. (2005). 'Applications of superconducting fault current limiters in electric power transmission systems', IEEE Transactions on Applied Superconductivity, 15(2):2130-3.

[64] Ghanbari, T., and Farjah, E. (2013). Unidirectional fault current limiter: An efficient interface between the microgrid and main network. IEEE Transactions on Power Systems, 28(2), 1591-1598.

[65] Zheng, F., Deng, C., Chen, L., Li, S., Liu, Y. and Liao, Y. (2015). 'Transient performance improvement of microgrid by a resistive superconducting fault current limiter', IEEE Transactions on Applied Superconductivity, 25(3):1-5. 
[66] Kim, S. Y., and Kim, J. O. (2011). Reliability evaluation of distribution network with DG considering the reliability of protective devices affected by SFCL. IEEE Transactions on Applied superconductivity, 21(5), 3561-3569.

[67] Vilhena, N., Taillacq, A., Pronto, A., Murta-Pina, J., and Álvarez, A. (2016). Analysis of Electromagnetic Forces in Superconducting FaultCurrent Limiters Under Short-Circuit Condition. IEEE Transactions on Applied Superconductivity, 26(3), 1-4.

[68] Chen, L., Zheng, F., Deng, C., Li, S., Li, M., Liu, H., and Guo, F. (2015). Application of a modified flux-coupling type superconducting fault current limiter to transient performance enhancement of micro-grid. Physica C: Superconductivity and its Applications, 15;518, 144-148.

[69] UM, M. (2013). 'Harmonic Analysis of Superconducting Fault Current Limiters (SFCL)', International Journal of Scientific \& Engineering Research,.

[70] Choi, D. H., Yoo, J. I., Kim, D., Lee, S. H., and Park, J. W. (2017). Analysis on effect of SFCL applied to an isolated microgrid with a dynamic load model. IEEE Transactions on Applied Superconductivity, 27(4), 1-4.

[71] Zhu, J., Zheng, X., Qiu, M., Zhang, Z., Li, J., and Yuan, W. (2015). Application simulation of a resistive type superconducting fault current limiter (SFCL) in a transmission and wind power system. Energy Procedia, 75, 716-721.

[72] Moscrop, J. W., and Hopkins, S. (2009). 'Development and performance analysis of a saturated core high temperature superconducting fault current limiter, 1-6.

[73] Ghanbari, T., and Farjah, E. (2012). Development of an efficient solidstate fault current limiter for microgrid. IEEE Transactions on Power Delivery, 27(4), 1829-1834. 


\section{Biographies}

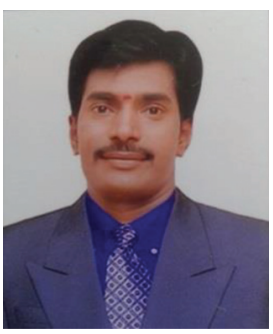

M. Poornachandra Reddy received B.Tech degree in Electrical and Electronics Engineering. M.Tech degree in PE \& ED from JNTUA. He is currently Research Scholar at the School of Electrical Engineering, VIT University, Vellore, India. His research interests are Power System Protection, Microgrid Technology.

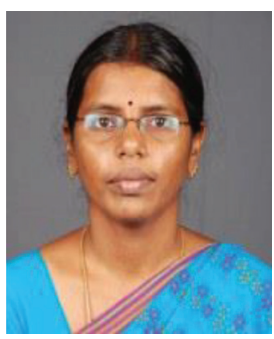

M. Manimozhi received B.E. in Electronics and Instrumentation, M.E. in Process Control and Instrumentation from Annamalai University and Ph.D in Process Control from VIT University, Vellore. She is currently Associate Professor at the School of Electrical Engineering, VIT University, Vellore, India. Her research interests include Process Control and Instrumentation, State Estimation, Health Monitoring, Sensors and Signal Conditioning. 
